\title{
Improvised Music Follows Human Language Quantitative Properties to Optimize Music Processing
}

\author{
Sarig Sela \\ The Hebrew University, Mt. Scopus, Jerusalem 9190501, Israel. \\ Email: sarig.sela@gmail.com
}

Publication status

Published. Sela, S. (2022). Improvised music follows human language quantitative properties to optimize music processing. Psychology of Music. https://doi.org/10.1177/03057356211061186 


\begin{abstract}
Music is a cognitively demanding task. New tones override the previous tones in quick succession, with only a short window to process them. Language presents similar constraints on the brain. The cognitive constraints associated with language processing have been argued to promote the Chunk-and-Pass processing hypothesis and may influence the statistical regularities associated with word and phenome presentation that have been identified in language and are thought to allow optimal communication. If this hypothesis were true, then similar statistical properties should be identified in music as in language. By searching for real-life musical corpora, rather than relying on the artificial generation of musical stimuli, a novel approach to melodic fragmentation was developed specifically for a corpus comprised of improvisation transcriptions that represent a popular performance practice tradition from the 16th century. These improvisations were created by following a very detailed technique, which was disseminated through music tutorials and treatises across Europe during the 16th century. These music tutorials present a very precise methodology for improvisation, using a pre-defined vocabulary of melodic fragments (similar to modern jazz licks). I have found that these corpora follow two paramount, quantitative linguistics characteristics: (1) Zipf's rank-frequency law and (2) Zipf's abbreviation law. According to the working hypothesis, adherence to these laws ensures the optimal coding of the examined music corpora, which facilitates the improved cognitive processing for both the listener and the improviser. Although these statistical characteristics are not consciously implemented by the improviser, they might play a critical role in music processing for both the listener and the improviser.
\end{abstract}

Keywords: Zipf's Laws; Ornamentation; Improvisation; Corpus Analysis; Quantitative Linguistics. 
[DRAFT VERSION]

\section{Improvised Music Follows Human Language Quantitative Properties to Optimize Music Processing}

Performing music requires astonishing levels of human skill. Regardless of whether music is performed from memory, read from a music sheet, or improvised, the number of different parameters that must be synchronized to produce music is overwhelming: duration, pitch, timbre, articulation, and volume are only one set of parameters required to control and render a single note (Burton, 2015, pp.22-28; Gardner 2011, p. 111). Higher levels of abstraction are required to produce music, even if the music is composed of only one monophonic stream of notes. These abstraction levels are expressed on a sequence of notes, rather than on any single note, such as accelerando/ritenuto, glissando, crescendo/diminuendo, which describe gradual changes in note sequences (Palmer, 1989; Poli, 2004; Shaffer, 1984). The ability to group sequences of notes into higher syntactical and conceptual units allows for the generation of hierarchical structures. Each level of structure relates to other structures, at the same level or between different levels, according to their associated properties (Peretz, 1989; Tan et al., 1981). For example, to group note sequences, one can use a special delimiter to segment the note sequences (Lerdahl \& Jackendoff, 1983, pp. 45-52; Pearce, Müllensiefen, \& Wiggins, 2010; Temperley, 2001; Thom, Spevak, \& Höthker, 2002), as demonstrated in Figure 1. Once a group has been defined, it can be used as a building block for the next abstraction level. If note grouping and the creation of building blocks are not defined arbitrarily but, instead, can be

formulated according to a set of combinatorial and compositional rules, then these rules would represent a syntax for the stream of notes. 


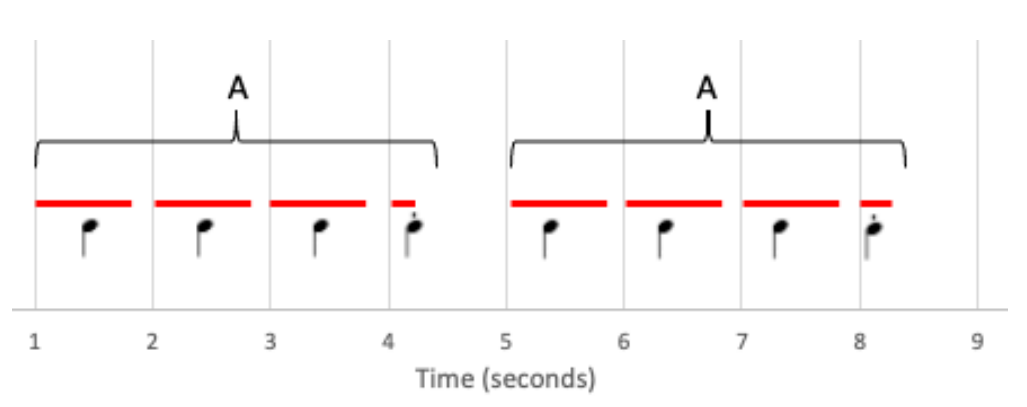

Figure 1. A staccato of the fourth note acts as a delimiter for note grouping. A group can be defined as one element (A) for the next surface (red line marks the sound of a note).

The differentiation between various combinatorial and compositional rules defines musical styles.

Music is a temporal domain. Once the note duration is over, no traces of the auditory stimuli remain. ${ }^{1}$ The order of the notes must be remembered by the listener to be able to process the stream.

In this paper, I define music processing as a bi-directional process through which a performer renders a stream of notes by applying a syntax, which is stored at higher abstraction levels, whereas a listener executes the reverse processing events to reconstruct higher abstraction levels by applying the same syntax rules to a stream of notes.

In summary, a monophonic stream of music bears three characteristics that are germane to this discussion: (1) a hierarchical structure that is defined by a set of rules (syntax); (2) temporality, as the auditory stimuli fade out; and (3) the significance of the order in which the notes are rendered in the stream.

\footnotetext{
${ }^{1}$ Up to the level of an acoustical echo effect, during which previous notes might overlap with the current notes of a sequence for a limited timeframe.
} 


\section{[DRAFT VERSION]}

Human language exhibits similar attributes as those in music. Humans can speak extemporaneously by recombining meaningless speech sounds, referred to as phonemes, into meaningful units, known as morphemes and words, which are combined into higher-level constructs, e.g., sentences and paragraphs (Brent, 1999; Jusczyk, 1997). The combinatorial and compositional rules for reconstructing these structures are particular to each language and constitute elements of the acquired knowledge that both the speaker and the listener must possess to be able to process language. Understanding the properties of these combinatorial and compositional rules, which define language structures, is a central goal of cognitive science (Harris, 2006).

Christiansen and Chater (2016) coined the term Now-or-Never bottleneck to describe a key premise of language processing, which states that "if linguistic information is not processed rapidly, that information is lost for good." They claimed that this pressure on the brain has fundamental implications for language processing, acquisition, and change, which is likely to affect the structure of language itself.

Moreover, Christiansen and Chater (2016) suggested that the Now-or-Never bottleneck was a dominant influence (although not necessarily unique) to the development of a cognitive process hypothesis, named Chunk-and-Pass, to overcome this constraint. Chunk-and-Pass is described as a component of the brain's comprehension system that breaks received stimuli into groups, which are recoded and compressed into chunks of information, which are then passed to a higher level of comprehension processing (Figure 2). Christiansen and Chater suggested that these chunks may be compressed in a lossy manner, such that not all of the information can be decoded at higher levels of comprehension. Moreover, the chunks themselves might not be 


\section{[DRAFT VERSION]}

recombined into a single object, which can result in shallow and sometimes inaccurate interpretations.

The Chunk-and-Pass process is bi-directional. Theoretically, the speaker is assumed to start the speech process at a conceptual level, which is then broken down into words that are further divided into articulated phenomes via speech. In contrast, the listener is believed to perform the opposite processing to rebuild the structure, starting with the identification of the phonemes and ending with the construction of the concept.

Working memory plays a crucial function during the processing of temporal stimuli because once an information element (i.e., notes or morphemes) has passed its duration, it is gone forever. The appearance order of temporal, arbitrary stimuli elements has been demonstrated to be restricted in the short-term memory (STM) at ranges of $7 \pm 2$ (Miller, 1956) to $4 \pm 1$ items (Cowan, 2001).

Although the stimuli stored in STM appear to be very small relative to the size of higherlevel constructs (such as sentences or musical phrases), humans are still capable of impressive processing capabilities. This capability increases when the stimuli are not random but are instead generated by a guided schema. For example, English speaking and listening rates are typically 150 words per minute, which corresponds to approximately $10-15$ phonemes or 5-6 syllables per second (Studdert-Kennedy, 1986). This high level of processing performance contrasts with the much poorer performance detected when the stimuli is a sequence of arbitrary auditory signals, such as a low-pitched tone $(600 \mathrm{~Hz})$, a high-pitched tone $(1000 \mathrm{~Hz})$, and a broadband noise (Warren et al. 1969).

A similar effect on performance was described by Sloboda (1982, p. 485), who reported that the eye-hand span (EHS), i.e., the amount of reading ahead, was typically six or seven notes 
for good readers and three or four notes for poor readers, but that the performances of both good and bad readers decreased when the sequence was random.

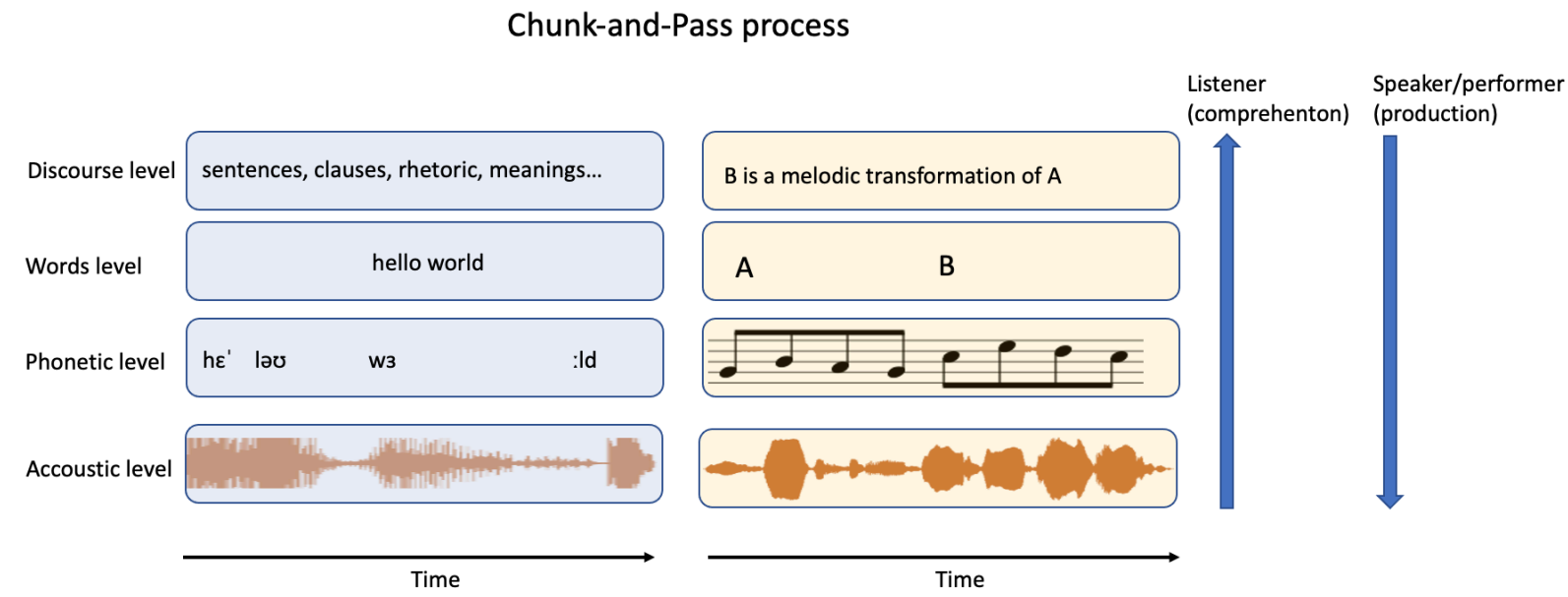

Figure 2. Chunk-and-Pass process. The speaker/performer decodes abstract information units into more concrete units, whereas the listener encodes information units into more abstract units.

The positive correlation between poor performance and the level of randomness in the presented stimuli can be explained by Shannon's (1948) information theory concepts. The effectiveness of compression can be measured using a data compression ratio, which is the ratio between the length of the uncompressed stimuli (represented as a sequence of elements) and the length of the compressed stimuli, such that a smaller ratio indicates less effective compression. Shannon (1948) indicated that more random uncompressed stimuli are associated with smaller compression ratios, resulting in longer compressed outputs, which might explain the experimental results reported by Warren et al. (1969) and Sloboda (1982, p. 485) suggesting that poor performance is associated with poor compression ratios.

Therefore, investigating the relationship between stimuli organization and compression ratios is necessary to evaluate whether the Chunk-and-Pass process effectively encodes 
information gathered at each abstraction level (based on effective compression ratios) to address and overcome the proposed Now-or-Never bottleneck.

Two of Zipf's laws (Zipf, 1936, 1949) appear to shed light on the relationship between the compression ratio and the organization of input data. The law of abbreviation claims that as words occur more frequently in a human language, they tend to become shorter (Figure 3). The law of abbreviation has been verified in 986 human languages (Bentz \& Ferrer-i-Cancho, 2016), and is included in the animal communication systems of Formosan macaques and common marmosets, in the surface behavioral patterns of dolphins (Ferrer-i-Cancho et al., 2013), and in the Unix operating system (OS) command-line interpreter (Ellis \& Hitchcock, 1986). Therefore, this rule does not appear to be specific to any particular language but is a universal property of human languages.

The abbreviation law can be defined mathematically as follows:

$$
\operatorname{Corr}(L, F)<0
$$

where the magnitude of words (L) stands in negative (not necessarily proportionate) correlation to the number of occurrences (F). 


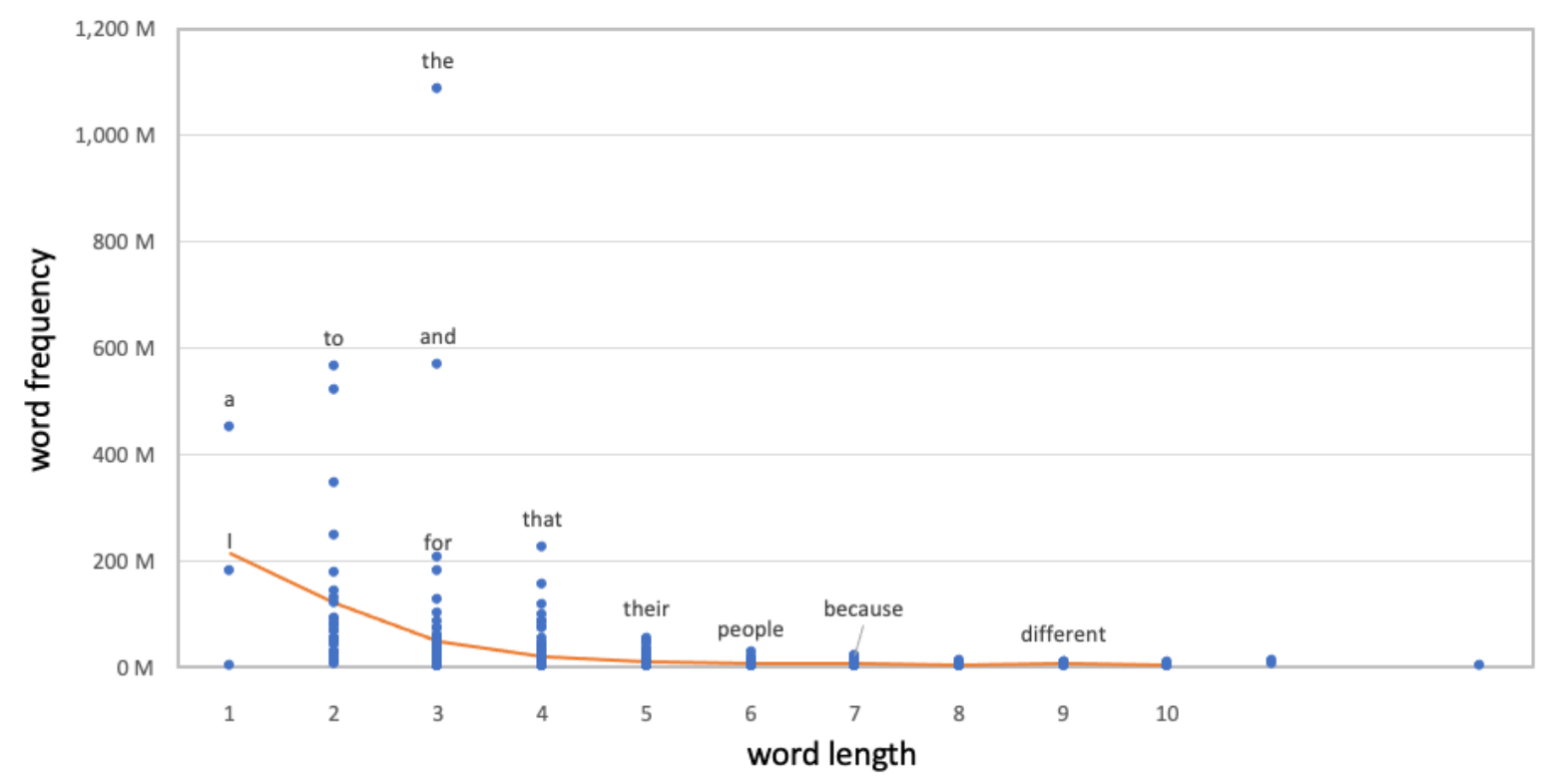

Figure 3. The 500 most frequent words, taken from the Corpus of the English Web 2013

(https://sketchengine.co.uk/wp-content/uploads/word-list/english/english-word-list-total.xls). The corpus size

is 19 Billion words. Each word is represented by a single point (only some points are labeled). The law of abbreviation states that the more frequently a word appears, the shorter it tends to be. The red line represents the mean frequency of words, according to the word length in letters.

The other regularity identified by Zipf, often considered to represent the best-known law in quantitative linguistics, is known as the rank-frequency law, which claims that the most frequent word in a given corpus of language will occur approximately twice as often as the second-most frequent word, three times as often as the third-most frequent word, and so on. This law also has been verified in most written and spoken languages (Bian et al. 2016; Piantadosi, 2014).

This occurrence distribution frequency is called a Zipfian frequency and is mathematically defined as follows:

$$
F \propto \frac{1}{R^{a}}, \text { where } \alpha \approx 1,
$$

$\mathrm{R}$ is the word's occurrence rank and $\mathrm{F}$ is its frequency 


\section{[DRAFT VERSION]}

The combination of these two laws allowed Mandelbrot $(1953,1961)$ to mathematically prove that if an input stream follows a near-Zipfian ${ }^{2}$ distribution and the more-frequent words are short, then the processing cost of words is minimized for average information content. Following Mandelbrot's derivations, a few researchers have claimed that Zipf's laws provide a mechanism for the maintenance of effective communications (Ferrer-i-Cancho, 2005a, 2005b; Mandelbrot, 1961; Salge et al., 2015; Zipf, 1936, 1949). For example, Ferrer-i-Cancho (2016) has suggested that the reoccurrence of Zipf's distribution across multiple human languages could originate from the realistic pressure of the Now-or-Never bottleneck (Christiansen \& Chater, 2016) of linguistic processing.

The structure of the optimal communication for processing argumentation is shown in Figure 4.

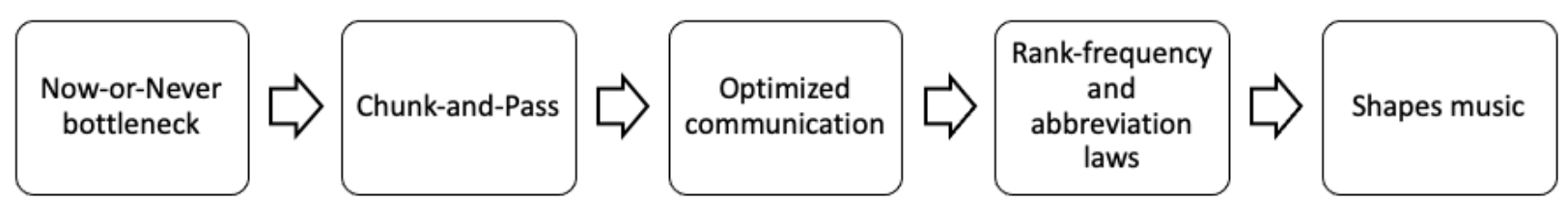

Figure 4. The structure of the optimal communication for processing argumentation. The Now-orNever bottleneck represents a catalyst for the Chunk-and-Pass strategy to address the problem faced by cognitive capabilities bounded by limited resources. To enhance the effectiveness of the Chunk-and-Pass strategy, the input (music) is optimized by following the rank-frequency and abbreviation laws, which also impact the generation of music.

Zipf's rank-frequency law has been demonstrated not only in language but also in many other areas of science (Farmer \& Geanakoplos, 2008; Mitzenmacher, 2004; Newman, 2005;

\footnotetext{
2 The term near-Zipfian is used more broadly to describe frequency distributions that approximate the expected results based on Zipf's rank-frequency law.
} 


\section{[DRAFT VERSION]}

Saichev, Malevergne et al., 2011). Several papers have demonstrated a Zipfian distribution for musical elements (Hsü \& Hsü, 1991; Lerdahl \& Jackendoff, 1983; Manaris et al., 2003, 2005; Voss \& Clarke, 1975, 1978).

None exiting papers (to my knowledge) in the field of music have attempted to explain the phenomenon of Zipfian distribution from a communication optimization perspective, which may be due to a lack of evidence that these derivations are based on Zipf's law of abbreviation. For example, Manaris et al. (2005) and Zipf himself (1949) examined single melodic intervals to demonstrate Zipf's rank-frequency law. However, comparing single melodic intervals to words is problematic due to the magnitude of the inventory of elements, as most melodies are constrained by an octave and a half, limiting the maximum possible number of melodic intervals to choose from to 18 , whereas more than 150,000 words exist in the English language.

A more productive analogy, in terms of the magnitude of elements, would be to compare letters (or phonemes) to intervals and to compare words to interval sequences. Manaris et al. (2005) appeared to have considered these comparisons and were able to demonstrate Zipfian distributions by breaking melodies into binary and ternary sequence intervals rather than single note occurrences.

Breaking melodies into fixed-length sequences to serve as abstraction layers can be challenging because melodies are not typically grouped by fixed-length elements; they are grouped according to syntactic rules, as formulated by music theoreticians (Lerdahl \& Jackendoff, 1983; Schenker, 2001). Therefore, notes are generally grouped into different sizes depending on the syntax. In language, fixed-length is not productive either, as grouping letters into fixed lengths without considering the boundaries of words leads to an increase in the inventory size. For example, a sentence such as: "good morning everyone" will be grouped into a 
meaningless sequence of morphemes (or symbols) instead of into meaningful words (in this example, good $\mid$ morn $\mid$ inge $\mid$ very $\mid$ one $)$.

The two Zipf laws have been verified to be valid for a variety of corpora, including corpora that comprise scientific texts and corpora that comprise literature (like reading books). Moreover, the Zipf laws have also been verified to apply to spoken language, in which the speakers and listeners process extemporaneous data. However, the argument that the Now-orNever bottleneck serves as a catalyst for communication optimization is stronger for spontaneous speech because writing and reading are less temporal. The writer can plan and change the text as much as desired, and the reader can read a sentence as many times as desired. However, spontaneous speech and written language (or pre-planned speech) are believed to have influenced the structures of the language. Therefore, the same characteristic statistical regularities have been identified in both spontaneous speech and written language even though, theoretically, the Now-or-Never bottleneck should be a less dominant influence on the written language. The same assumption applies to music: improvisation and composed music both influence the structure of music; therefore, similar characteristic statistical regularities are expected to be identified for both improvised and composed music.

In this paper, I would like to go a step further than Manaris et al. (2005) by examining both the rank-frequency law and the abbreviation law established by Zipf. These two laws are paramount characteristics of quantitative linguistics and are considered to be universal to all languages. I have examined melodic fragments taken from three special corpora of 16th-century transcriptions of improvisation practice to examine their adherence to these two laws. 
I present a novel approach used to extract melodic fragments from a melody using 16thcentury cultural and performance practice theories while preserving cognitive considerations based on modern theories, including GTTM and IR.

The finding that these musical improvisations adhered to Zipf's laws supported the claim that communication optimization in human languages occurs in all examined corpora. The results of this study revealed parallels between the statistical characteristics of the examined corpora and human languages. The hypothesis that the Now-or-Never bottleneck serves as a catalyst for cognitive mechanisms and the statistical regularities that underlie the cultural influences of different musical styles was strengthened by these findings.

\section{Methods}

To examine the hypothesis that statistical similarity exists between meaningful melodic fragments and human language morphemes, I attempted to identify a musical style in which melodic segmentation could be inferred, without ambiguity, from a well-defined model.

No consensus has been reached regarding how to segment a stream of any genre of melodic sequences into meaningful elements (the equivalent of words or morphemes in language) among music scholars (Cambouropoulos et al., 2001; Crawford et al. 1998; Lidov, 1979; Lerdahl \& Jackendoff, 1983; Meredith et al., 2002, Narmour, 1990, 1992; Pearce et al., 2010; Rolland \& Ganascia, 2000; Spevak, Thom, \& Höthker, 2002). A few widespread theories have attempted to address the subject of melodic segmentation by offering different sets of rules. Prominent examples of such theories include the generative theory of tonal music (GTTM), presented by Lerdahl \& Jackendoff (1983) and based on Gestalt principles, and Narmour's Implication-Realization (IR) model (1990, 1992), which is based on similar Gestaltian principles, 
with an emphasis on the dynamics of music over time and the intervallic expectations of music. These proposed rules for segmentation are associated with various music fundamentals, such as melody, rhythm, and, in some cases, harmony. However, segmentation ambiguities can arise when the fundamentals contradict each other, and these types of ambiguities (Figure 5) often occur in music.

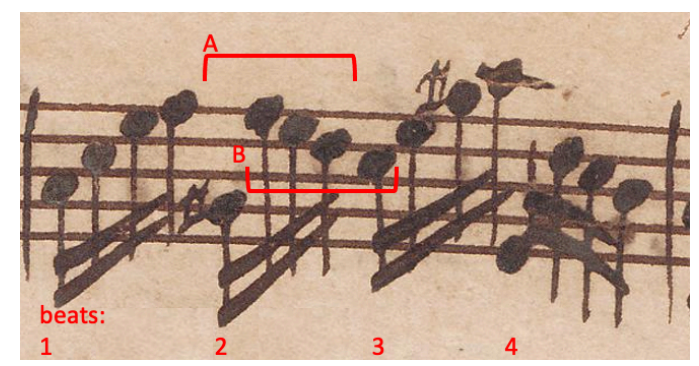

Figure 5. Example of ambiguity in a melodic segmentation. ${ }^{3}$ Taking rhythmical and harmonical considerations suggests the grouping of the second beat, as shown in option A, due to a harmony change (E7 $\rightarrow \mathrm{Am})$ and the onset of the third beat. In contrast, all of the melodic intervals are stepwise, except for the first interval (a $7^{\text {th }}$ interval), which suggests the grouping proposed by option $B$.

Unlike functional utterances, where ambiguity represents a disadvantage, in music, ambiguity provides depth and additional meaning. However, segmentation ambiguity must be resolved, as performance must be rendered to only one option. Figure 6 shows an example of how the two grouping options might be rendered.

\footnotetext{
${ }^{3}$ The excerpt is the second bar of the first movement of Bach's partita for solo flute, in A minor, BWV 1013.
} 


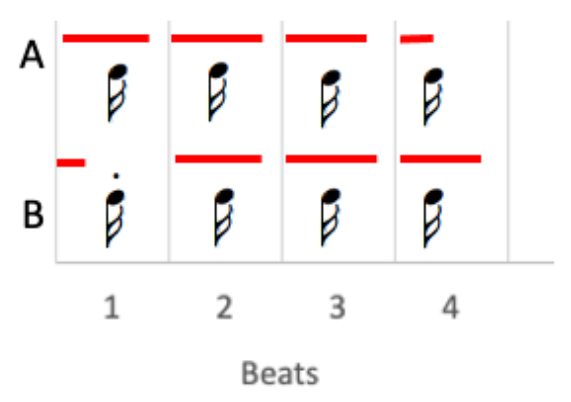

Figure 6. The resolution of grouping must occur at the same time that music is performed. This figure presents one option for how to express the different grouping options that appear in Figure 5Error! Reference source not found..

The resolution depends not only on gestalt, cognitive, or computational theories but also on culture (Spevak et al., 2002; Thom et al., 2002). The aesthetics of the musical style and period, the performance practice, and the theory used to support the creation of the composition are all dominant parameters in the grouping process. The same melody might change its note grouping performance based solely on the period during which it was written.

Therefore, when comparing the regularities between language and music, the method used to segment the melody into meaningful fragments must be carefully considered. The minimal threshold requirement for segmentation might be the avoidance of contradicting the main cognitive theories, such as the GTTM and IR models. If segmentation rules are defined by considering a given period's cultural aesthetics, performance practices, and compositional theories, then the segmentation process is likely to be even more reliable than solely cognitive considerations because the segmented chunks are likely to reflect the process used to construct the music and can be used to identify the building blocks that were actually in use.

Therefore, to minimize the ambiguity of segmentation I chose a very specific type of music genre, improvisations of $16^{\text {th }}$ century music, to serve as a corpus. In this music genre, the segmentation algorithm is well-defined and agreed upon in all the treatises of the $16^{\text {th }}$ century. 
Therefore, at least for the theoreticians of the $16^{\text {th }}$ century, the corpus provides a consensus of the melodic building blocks.

Moreover, a model that was designed specifically for improvisation, rather than for pure composition, was preferable because the main research hypothesis suggests that the Now-orNever bottleneck serves as a catalyst for the Chunk-and-Pass processing theory and the establishment of statistical regularities. An improvisation setting ensures that the Now-or-Never bottleneck pressure is high, not only for a listener who is hearing the composition for the first time but also for the performer who invents the improvisational fragments on the fly.

The chosen style for the experiment was 16th-century division ornamentation practice (DOP). DOP proliferated during the 16th century and the first two decades of the 17th century. Eleven division instruction manuals were published by improvisers to help assist professional and novice musicians in the acquisition of DOP skills. ${ }^{4}$ In DOP, the performer is expected to improvise ornamentations on the melodic line of a well-known composition. The compositions were typically the polyphonic music of madrigals, chansons, and motets.

The improvisational section was typically not implemented by inventing melodic sequences from scratch but instead by choosing pre-defined melodic sequences (which will be referred to as figurations in this paper) and creatively recombining them. A substantial portion of the division instruction manuals was used as suggestions for figurations to be used.

\footnotetext{
${ }^{4}$ The division instruction manuals from the $16^{\text {th }}$ century and the beginning of the $17^{\text {th }}$ century: Ganassi (1535); Ortiz (1553); Dalla Casa (1584); Bassano (1585); Rognoni (1592); Conforti (1593); Bovicelli (1594); Virgiliano (ca. 1600); Brunelli (1610); Rognoni-Taeggio (1620); Spadi (1624).
} 
Syntactic rules exist that govern which figurations are considered to be valid for embedding into various melodic contexts. Each improviser was intended to memorize the predefined figurations presented in the division instruction manuals and to execute them during improvisation. In this sense, the figurations are similar to words that are retrieved from memory when parsing sentences.

The sources available for musicologists to learn about DOP include (1) improvisation transcriptions of famous improvisers of the time, such as Bassano, Dalla Casa, and Ortiz. In this paper, I used these sources to create the corpora (2) division manuals, designed to teach musicians how to acquire the DOP technique, which represents a unique type of music treatise. The division manuals provide a well-defined model describing the algorithm necessary to apply the DOP technique. In addition, the division manuals included a 'dictionary' (as mentioned above) of thousands of pre-defined melodic fragment sequences to be applied as improvisation fragments (the equivalent of Jazz licks or riffs). I used the model to reverse engineer the improvisational process and to extract the melodic fragments into groups (these represent the musical building blocks and are equivalent to human language morphemes). Some of the manuals also provide a philosophical, cultural, and aesthetic framework for DOP. (3) Scholarly treatises can provide quantitative advice, rules of thumbs, and aesthetic and philosophical context; however, I did not use any of these sources in this paper.

\section{The corpora}

Bassano's corpus consists of all of his transcribed improvisations. In Motetti, Madrigali et Canzonie Francese (1591), 37 Soprano divisions and seven Bass divisions can be found; 
however, six viola bastarda divisions were omitted. ${ }^{5}$ From his Ricercate publication (1585), two additional Soprano divisions, written upon Rore's madrigal Signor mio caro, were included in the corpus.

Dalla Casa's corpus consists of all of his 91 transcribed divisions (I omitted the bastarda divisions). His transcriptions are published in the two-part 1584 treatise $I l$ vero modo di diminuir. Ortiz's corpus consists of eight transcribed improvisations: four on the madrigal ' $O$ Felici Occhi Miei' and the other four on the cancion 'Dolce Memoire' (Ortiz, 1553).

\section{The model for generating an improvisation, as defined in the 16th-century division manuals}

The first instrumental division manual, called Opera Intitulata Fontegara, was published by Sylvestro Ganassi, a musician of the Doge, in Venice in 1535. Fontegara is a recorder tutor that contains a large section describing DOP. It is unique, not only from a historical outlook but also from the viewpoint of this paper, as it provides a 'bilingual' dictionary and an algorithm for how to use the dictionary to improvise.

The dictionary structure of the manual is a collection of pairs. Each pair is composed of a key and multiple values. I call each of these values a figuration. In this paper, a figuration is the equivalent of a morpheme, an equivalence that will be demonstrated later. The key is composed of a sequence, ranging from two to five notes. Each figuration is a melodic fragment unit,

\footnotetext{
${ }^{5} \mathrm{~A}$ viola bastarda division is a special form of division, as its figurations are based on more than one specific voice of the original piece. Therefore, figuration extraction from these divisions is not deterministic.
} 
constructed from a longer melodic sequence of shorter note values than its associated key, in which the first note and the last note of the figuration have the same pitch class as the first note and last note of the key. Figure 7 shows an example of a melodic fragment that is meant to appear in the original melody and its associated figurations.

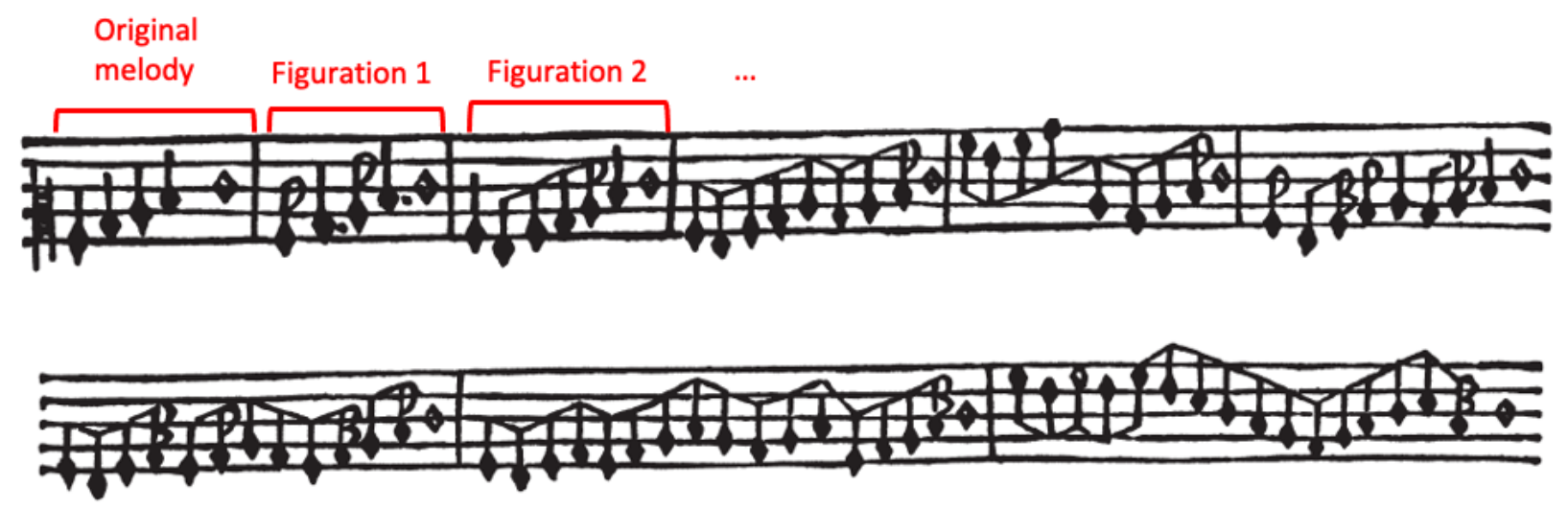

Figure 7. An excerpt from Ganassi's (1535) Fontegara manual. An example of figuration options for replacing a given melody fragment from the original composition. The improviser can choose any figuration, depending on his taste. The figuration's first and last notes are the same as the original melody's first and last notes.

The algorithm for how to use the dictionary is as follows:

1. Choose a melodic fragment from the original composition to be ornamented.

2. Identify the fragment using the keys of the dictionary.

3. Choose one of the corresponding values for the key and embed it into the original composition in place of the original melodic fragment.

In this model, three operations can be applied to the melodic fragment: 
1. Diatonic transposition (DT) - each key and value can be transposed diatonically to fit into the original melody of the composition.

2. Rhythmical transformation (RT) - each note in the key and value can be multiplied by a constant because the absolute duration of the notes is relative. Therefore, every key with quarter notes can be turned into half-notes or eighth notes.

3. Rhythmical alteration (RA) -some minor variations can be made to the rhymical patterns. For example, a sequence of four eighth notes can be turned into a dotted sequence pattern (a dotted eighth note and a sixteenth note).

Figure 8 shows an example of the operations that can be applied to a simple figuration.

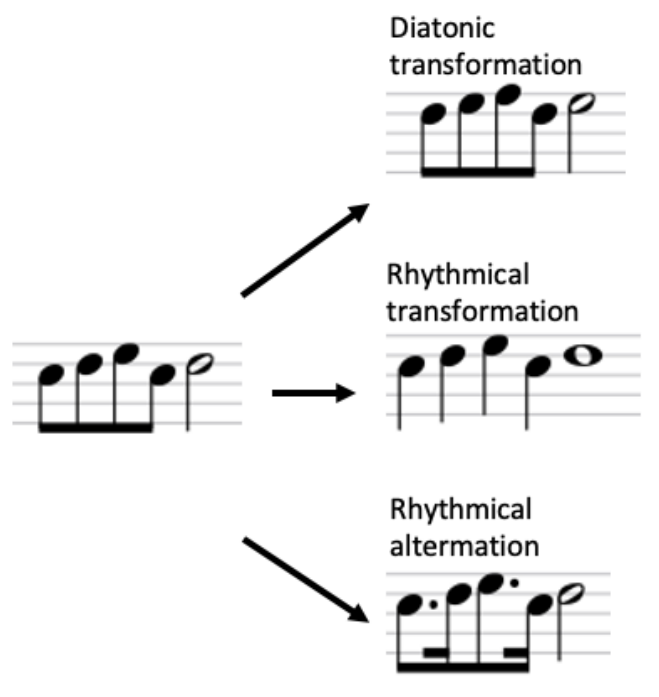

Figure 8. An example of the operations that can be applied to the figurations, as defined in the model. Another interesting case is when overlap exists between figurations, i.e., the last note of one figuration is the first note of the next figuration. The sequence of these overlapping 
figurations is referred to in this paper as chained figurations. Chained figurations allow the improviser to prolong the improvisation to span across many melodic sequences.

Figure 9 shows examples of chained and "simple" figurations. The brackets mark the figurations. Bracket 1 signifies a simple figuration, in which the last note of the figuration is not the beginning of the next figuration. In contrast, Figurations 2 and 3 share the same note $\mathrm{B}$ (marked in red) and, therefore, generate a chained figuration, marked by bracket 4 .

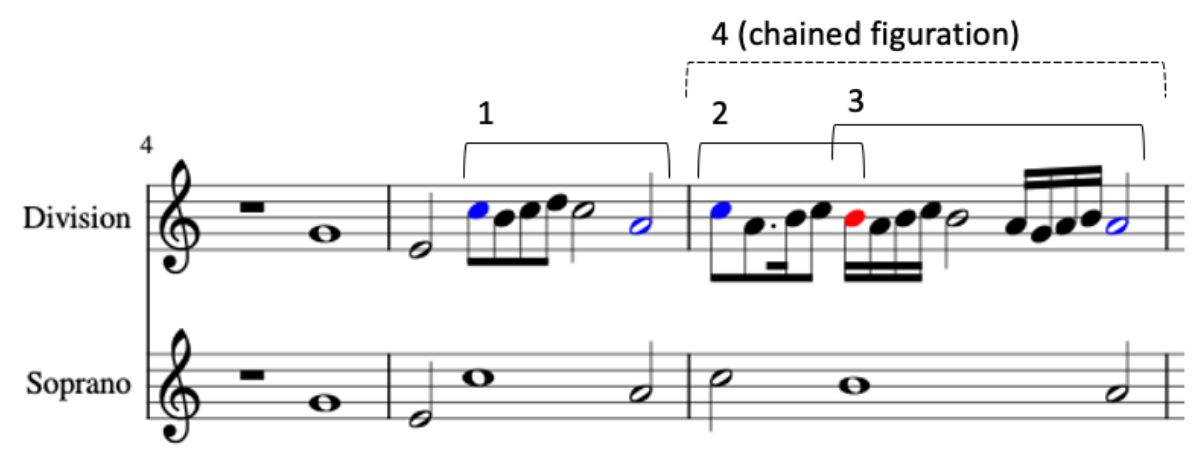

Figure 9. Example of chained figuration from Bassano's division upon Rore's madrigal Ancor che col partire. The red note is the last note of Figuration 2 and the first note of Figuration 3; therefore, the combination generates a chained figuration, indicated by Bracket 4.

\section{The model of melodic segmentation, based on the 16th-century model}

Based on the 16th-century model, I developed an algorithm to reverse engineer the improvisational process of embedding a figuration into the original melody and extracted the generated figurations. This algorithm segments the improvised versions based on 16th-century rules

The algorithm is shown in Figure 10. 


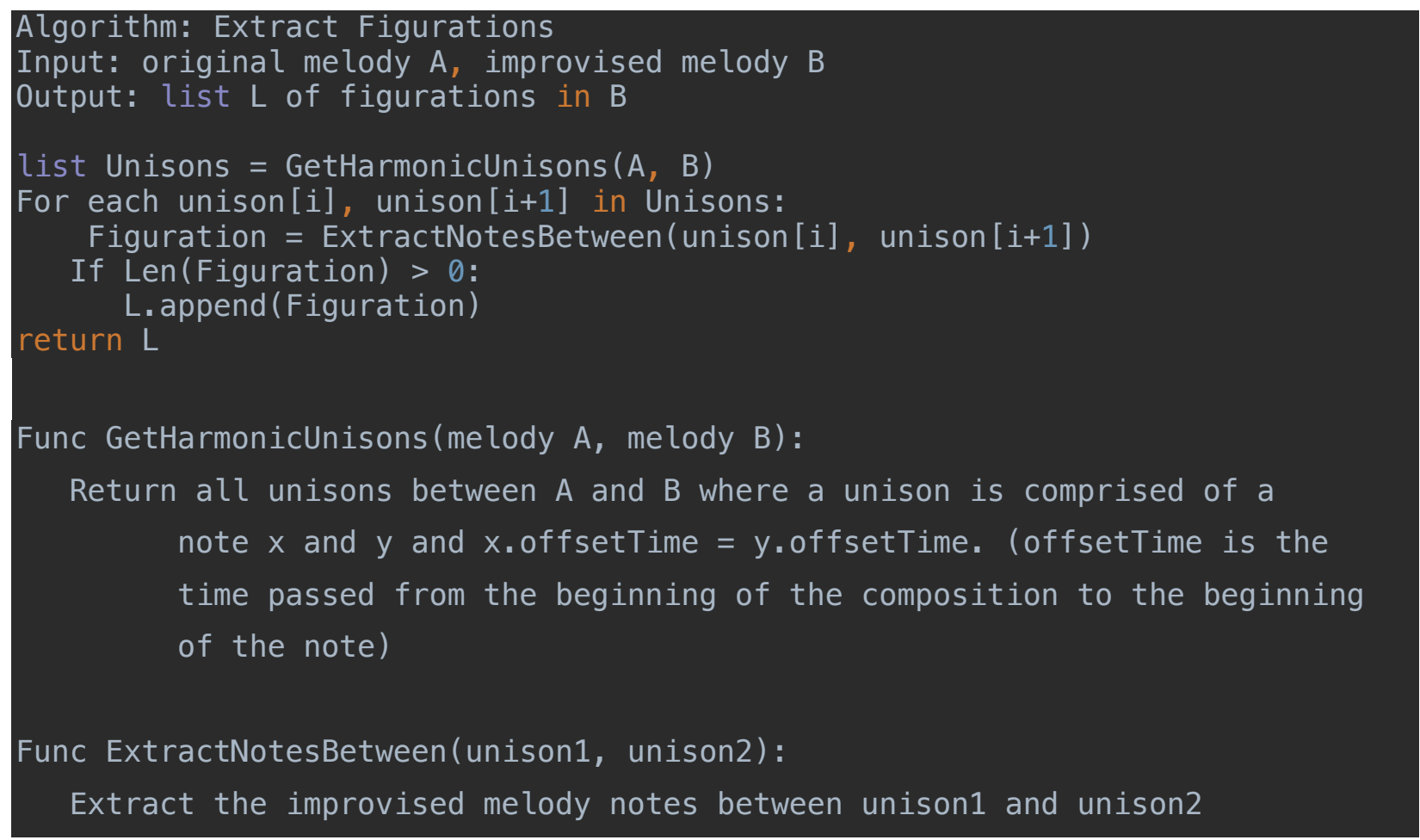

Figure 10. This algorithm was used to extract figurations from the improvised melody.

An example of the figuration extraction is shown in Figure 11

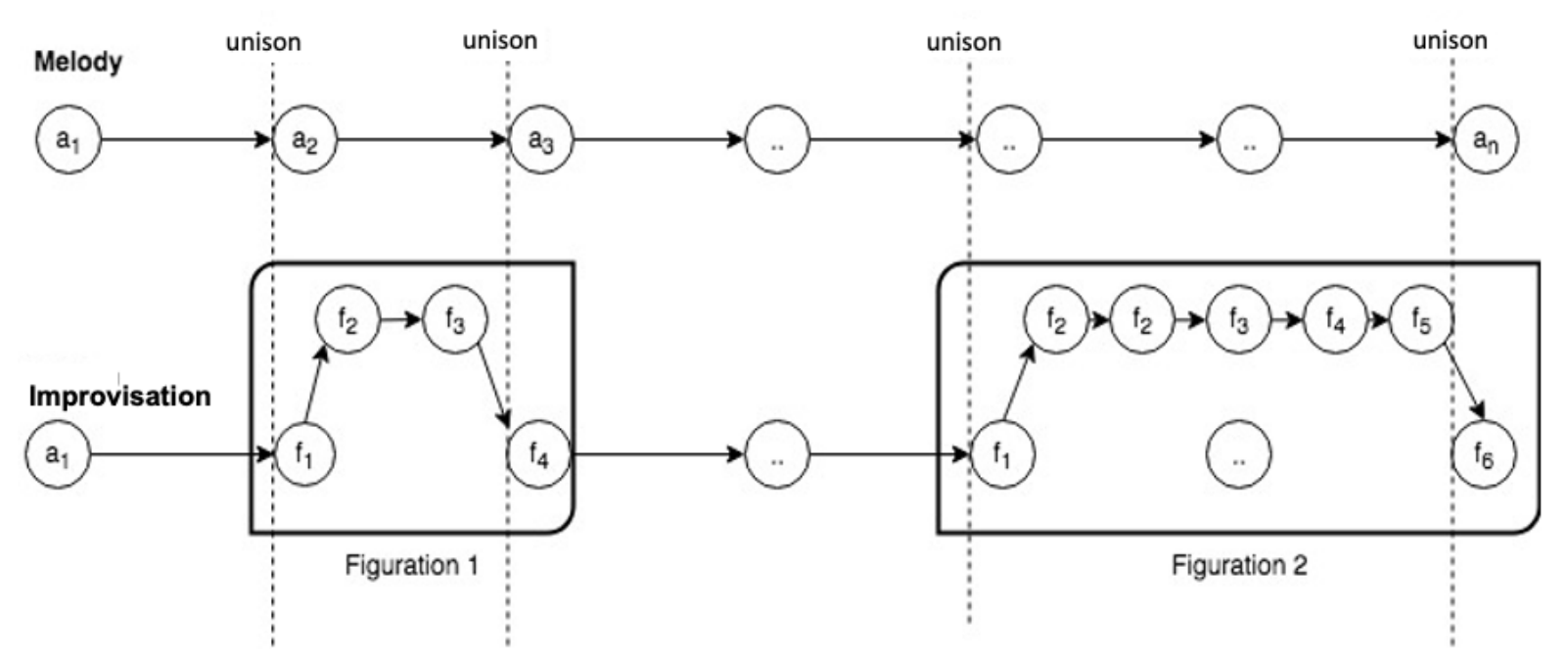

Figure 11. An example demonstrating how figurations are extracted from improvisations by comparing the improvisations to the original melody using the developed algorithm. 
The algorithm follows the figuration definition established by the 16th-century model and adheres to the rules established by cognitive reasoning: all of the figurations in the corpora begin and end on a relatively strong beat; their boundaries are always between a harmonic interval of the same pitch class (unison or octave), which is easily distinguishable and serves as a marker; and each figuration note is usually shorter (by two or more times) than the notes of the original composition.

\section{Figuration equality and figuration type definitions}

Let figuration $a=\left(a_{1} \ldots a_{n}\right)$ and figuration $b=\left(b_{1} \ldots b_{n}\right)$ where $a_{i}, b_{i}$ are notes.

Equality between figurations indicates that all the notes that comprise the figurations have the same pitch and duration and appear in the same order. Mathematically, figuration equality can be defined as:

$$
a=b \text { iff } a_{i}=b_{i} \text { for each } i \text { in }(1 \ldots n) \text {. }
$$

Figurations have the same type if it is possible to turn one figuration into the other by using DT, RT, or RA. For example, each figuration in Figure 8 has the same type, as each can be transformed into one of the other figurations by using these DT, RT, or RA.

Mathematically this can be defined as follows:

Type $(a)=$ Type(b) iff exists a sequence of figuration operations ops $=\left(o p_{1} \ldots o p_{m}\right)$ such that

$$
\operatorname{op}_{m}\left(\ldots o p_{2}\left(\operatorname{op}_{1}(a)\right)\right)=b .
$$

the operations performed on figurations are DT, RT, and RA (as defined in the previous section) 


\section{Computational Tools}

I used the Music21 framework (Cuthbert, \& Ariza, 2010) to perform figuration extraction and Python 3 and SciPy library (Jones E., Oliphant T. E., Peterson P., 2001-) for all other statistical analyses.

\section{Results}

\section{Corpora figuration extraction}

Using the described algorithm, I extracted all figurations directly from the corpora, classified them by type, and calculated the frequency of occurrence for each figuration type, as shown in Table 1. This process was used to build a new dictionary for each improviser that itemises the figurations and the frequencies of their occurrence. In this format, each dictionary is superior to the 16th-century dictionaries provided by the division manuals because they also contain information regarding the frequency of occurrence for each figuration type. Moreover, these usage statistics were derived directly and automatically from the improvisations themselves, rather than from the performers' subjective views on which figurations were being used.

As observed, Oritz provided a relatively small sample of transcriptions and, therefore, uses fewer figuration types and instances. Bassano tends to reuse the same figuration types more frequently than the others.

\section{Table 1}

Extracted figurations from the Corpora

\begin{tabular}{lllll}
\hline & Bassan & Dalla Casa & Ortiz & Global \\
& 0 & & & \\
Figuration Instances & 2435 & 3482 & 463 & 6380 \\
\hline
\end{tabular}




\section{Table 1}

Extracted figurations from the Corpora

\begin{tabular}{lllll}
\hline Figuration Types & 771 & 1270 & 192 & 2233 \\
$\begin{array}{l}\text { Reuse of figuration types } \\
\text { ratio (Instances/Types) }\end{array}$ & 3.16 & 2.74 & 2.41 & 2.86 \\
No. of Transcriptions & 52 & 91 & 8 & 151 \\
\hline
\end{tabular}

\section{The rank-frequency law}

Figure 12 depicts the frequency distribution of the corpora figurations: the $\mathrm{X}$-axis represents figuration types, ordered by their rank from the most to least frequent. The Y-axis represents the frequency of each figuration type. As observed, the distribution of these figurations is fairly similar to human language distribution.

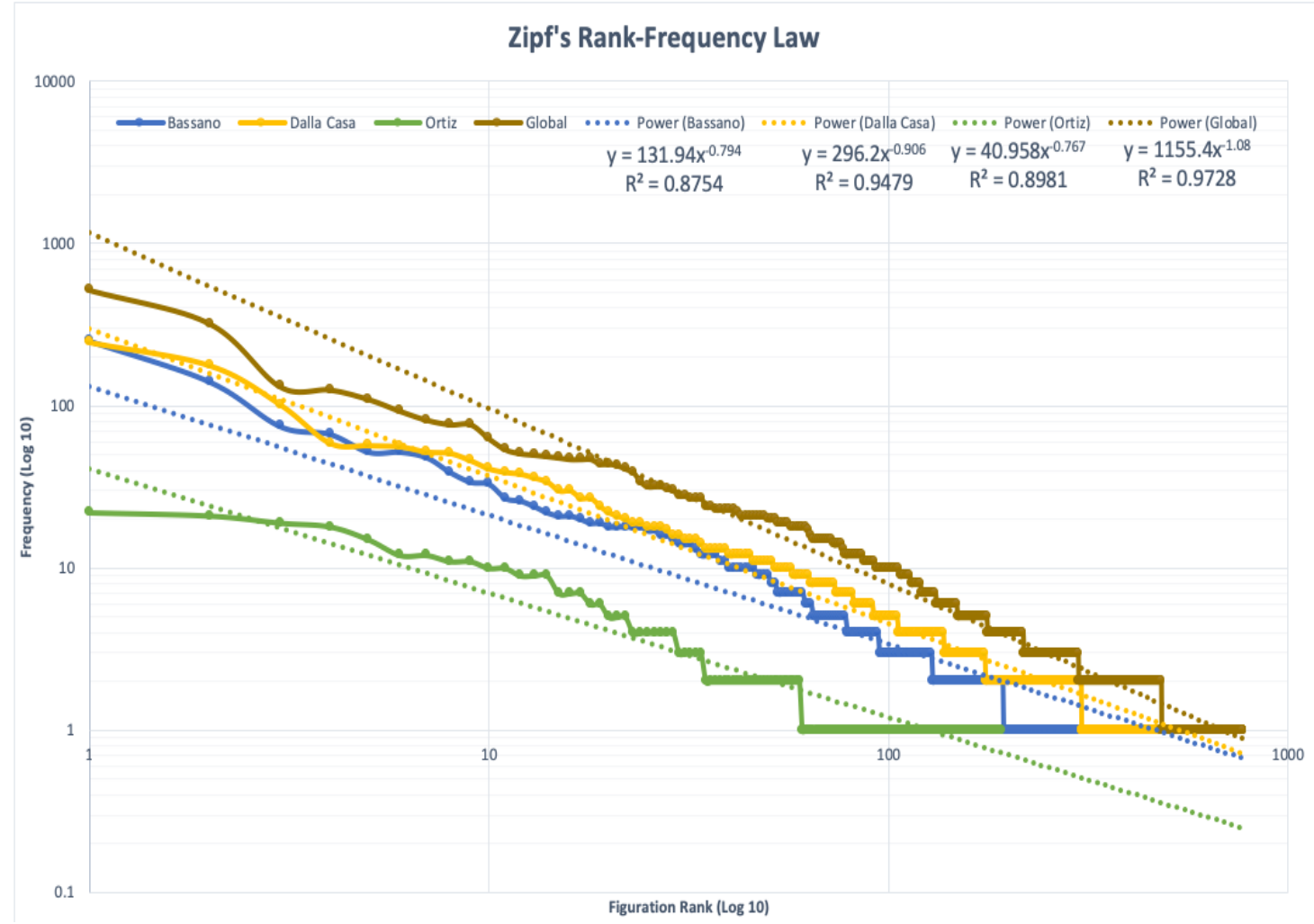

Figure 12. Corpora figuration histogram (log-log scale). A linear regression of the log-log scale shows a near-Zipfian distribution for each corpus, as well as the union of the corpora (labeled "Global"). 
Moreover, a recent study (Mehri \& Jamaati, 2017) calculated the range of values on a corpus that consisted of the Bible text translated into 100 languages. The study showed that the $\alpha$ values (defined in Equation 1) ranged from 0.765 to 1.442.

As observed in Table 2, the $\alpha$ values for each corpus were within the range found in Mehri \& Jamaati's (2017) study, associated with high coefficients of determination $\left(R^{2}\right)$ values; therefore, the corpora followed a near-Zipfian distribution, similar to natural languages.

\section{Table 2}

Linear regression of the log-log plot yields the following exponent $\alpha$ and $R^{2}$ values

\begin{tabular}{lcccc}
\hline & Bassano & Dalla Casa & Ortiz & Global \\
\hline$\alpha$ & 0.79 & 0.9 & 0.77 & 1.1 \\
\hline$R^{2}$ & 0.86 & 0.95 & 0.90 & 0.97 \\
\hline
\end{tabular}

\section{The abbreviation law}

To investigate the relationship between the frequency of each figuration type and its length, as described by Zipf's abbreviation law, the average frequencies of figuration types for each length value were calculated. A similar approach has been applied to human language corpora (Kanwal et al., 2017).

Zipf's word length can be interpreted in music using two reasonable methods:

Length can be described as the figuration sequence length, i.e., the number of melodic intervals that comprise the figuration sequence. Formally:

$$
\text { len }_{\text {seq }}(a)=n, \quad \text { for any figuration } a=\left(a_{1} . . a_{n}\right)
$$

Length can also be described as the figuration duration length, i.e., the duration summation of the figuration note sequence. Formally:

$$
\operatorname{len}_{d u r}(a)=\sum_{i=1}^{n} \operatorname{dur}\left(a_{i}\right), \quad \text { for any figuration } a=\left(a_{1} . . a_{n}\right)
$$


As shown in Figure 13 and Figure 14, the correlation between the frequency of a type and its length is non-linear, and the figuration type distribution is not normally distributed. Therefore, instead of using a linear association, such as the Pearson correlation coefficient, a Kendall and Spearman non-parametric rank-correlation coefficient was used.

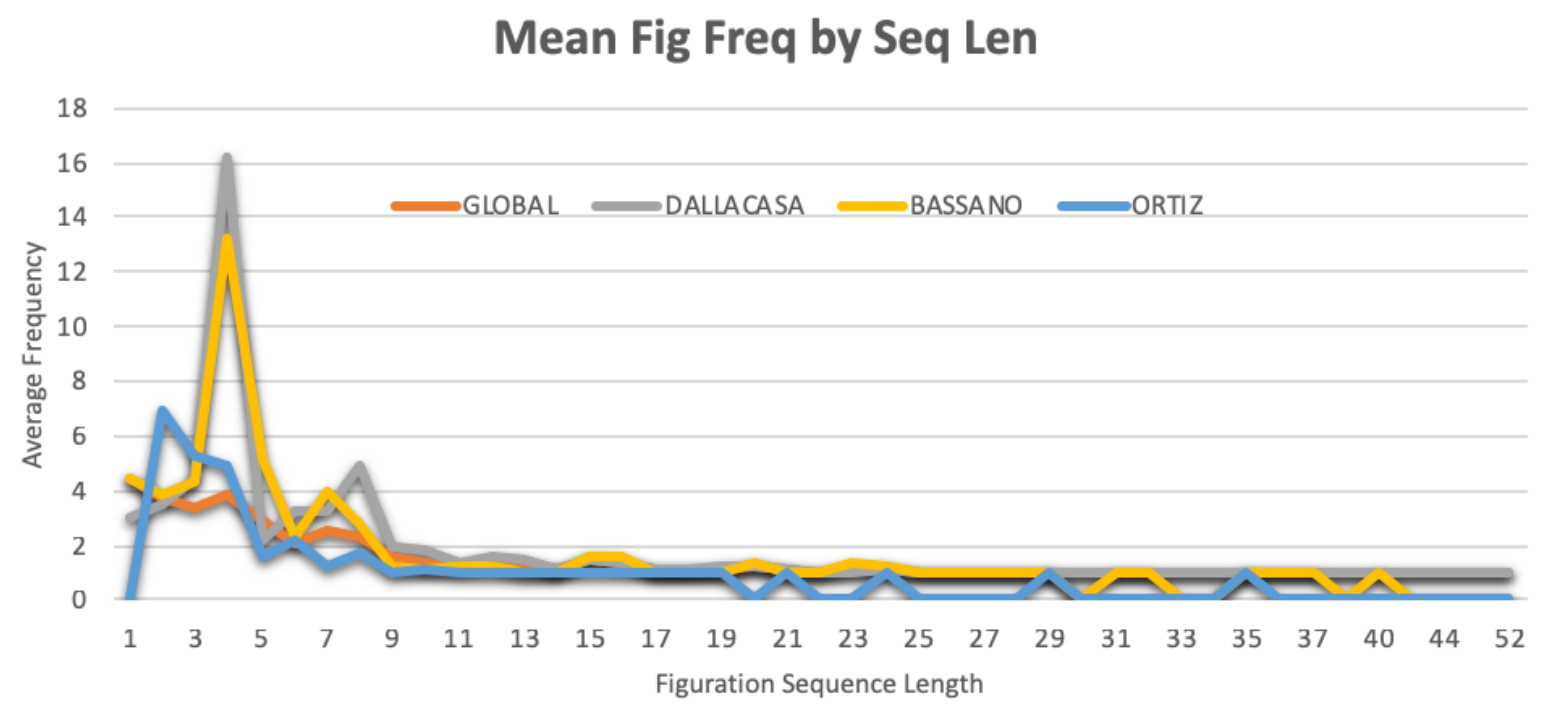

Figure 13. The average figuration frequency, as a function of the figuration sequence length.

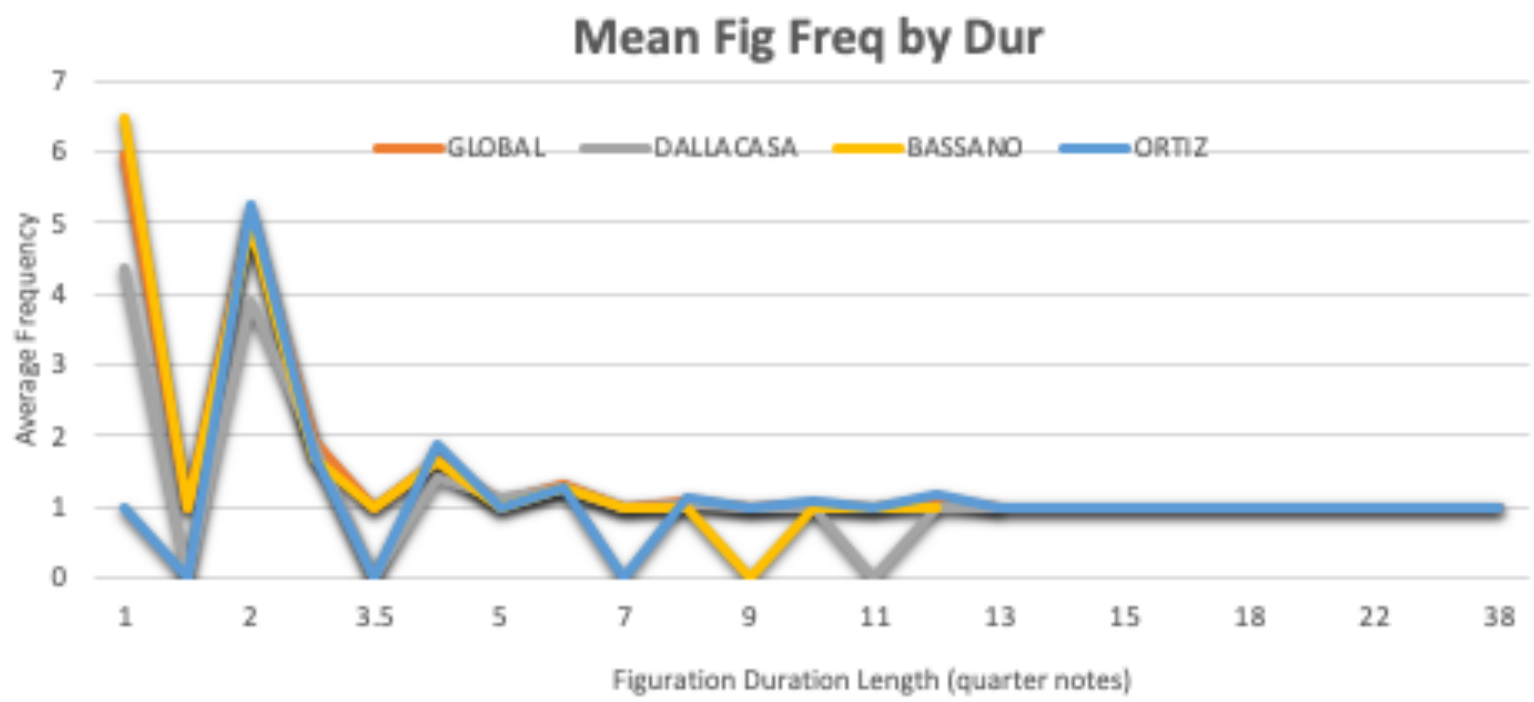

Figure 14. The average figuration frequency, as a function of the figuration duration length, measured in quarter notes. 
The correlation coefficient results demonstrated a moderate inverse relationship, which can be observed in Table 3. Therefore, the corpora followed the rule of abbreviation, as demonstrated in human languages.

\section{Table 3}

Inverse correlation between figuration type frequency and length.

\begin{tabular}{|c|c|c|c|c|c|c|c|c|}
\hline \multicolumn{3}{|c|}{ Bassano } & \multicolumn{2}{|c|}{ Dalla Casa } & \multicolumn{2}{|c|}{ Ortiz } & \multicolumn{2}{|c|}{ Global } \\
\hline \multicolumn{9}{|c|}{ Figuration sequence length } \\
\hline & value & p-value & value & p-value & value & p-value & value & $\mathrm{p}$-value \\
\hline$\rho$ & -0.347 & $3 E-23$ & -0.361 & $2 \mathrm{E}-40$ & -0.505 & $8 E-14$ & $\begin{array}{c}-0.36 \\
2\end{array}$ & $5 \mathrm{E}-63$ \\
\hline$\tau$ & -0.280 & $2 \mathrm{E}-22$ & -0.294 & $9 \mathrm{E}-39$ & -0.420 & $4 \mathrm{E}-13$ & $\begin{array}{c}-0.29 \\
2\end{array}$ & $4 \mathrm{E}-60$ \\
\hline \multicolumn{9}{|c|}{ Figuration duration length } \\
\hline$\rho$ & -0.346 & $3 \mathrm{E}-26$ & -0.343 & $2 E-41$ & -0.423 & $3 \mathrm{E}-11$ & $\begin{array}{c}-0.35 \\
3\end{array}$ & $6 \mathrm{E}-70$ \\
\hline$\tau$ & -0.279 & $3 E-25$ & -0.280 & $6 \mathrm{E}-40$ & -0.354 & $5 E-11$ & $\begin{array}{c}-0.28 \\
5\end{array}$ & $1 \mathrm{E}-66$ \\
\hline
\end{tabular}

Note: p-value denotes the two-sided values for a hypothesis test whose null hypothesis is an absence of association, i.e., correlation coefficient $=0 . \rho=$ Spearman's rank correlation coefficient; $\tau=$ Kendall's rank correlation coefficient.

\section{Discussion}

In this paper, I showed that statistical similarities exist in the organization of improvised 16th-century music and language. These similarities are exemplified by their adherence to the two paramount linguistic laws, identified by Zipf (1949): the rank-frequency and abbreviation laws. The music corpora in this paper consisted of 151 transcribed improvisations from the 16th century (Bassano, 1591; Dalla Casa, 1584; Ortiz, 1553). This study hypothesized that 16th- 


\section{[DRAFT VERSION]}

century improvisation practice aesthetics were influenced not only by culture but also by communicative optimization principles.

Moreover, the statistical regularities that were found were valid to all improvisers even though each improviser used his own unique vocabulary of figurations. The validity across vocabularies strengthens the universality property of the hypothesis as it is not bounded to a specific vocabulary. ${ }^{6}$

In language, communicative optimization has been suggested to be necessary for overcoming the Now-or-Never bottleneck constraint (Ferrier-i-Cancho, 2016; Pinatadosi, 2014). Because this same Now-or-Never bottleneck constraint exists in music, I suggest that the adherence to Zipf's laws in music occurs for the same reasons that these laws apply to language and, therefore, this case study serves as a concrete example that music is not only influenced by culture.

Although earlier studies of music have established that the rank-frequency law applies to melodic sequences (e.g., Hsü \& Hsü, 1991; Manaris et al., 2003, 2005; Voss \& Clarke, 1975, 1978), the abbreviation law, which is necessary for the communicative optimization hypothesis (Ferrer-i-Cancho, 2016) as a result of Mandelbrot's derivation (1953) was not able to be examined because the melody elements that have been used previously were constructed by dividing the melody into single, binary and ternary melodic sequence elements, in an arbitrary manner.

\footnotetext{
${ }^{6}$ The claim for universality of Zipf's laws have been examined across human languages, see Bentz \& Ferrer-i-Cancho, R. (2016)
} 
In this paper, I divided the melodies into their building blocks, called figurations, according to the syntactic rules defined by 16th-century theoreticians (e.g., Conforti, 1593; Ganassi, 1535; Ortiz, 1553) of the period. These rules also adhere to modern cognitive melodic segmentation theories (e.g., GTTM and IR). This syntactically aware method yielded melodic elements of variable lengths called figurations. In the 16th century, every professional and amateur musician was expected to learn and apply these figurations according to the syntactic rules of the period. I have demonstrated that these figurations, with their variable sequence lengths, follow the abbreviation law similar to all natural languages. This adherence to Zipf's laws suggests that the communicative optimization claim is valid, not only for language but also for the musical corpora I examined.

Moreover, discovering that statistical similarities exist between language and music (as expected based on the Now-or-Never bottleneck hypothesis regarding the processing of information) suggests that either a shared neural network exists in the brain that processes both language and music (as the domain-general theory posits) or that the two modalities (language and music) are processed by different areas of the brain using a common mechanism that is sensitive to these statistical characteristics.

Nevertheless, the corpora I examined was not a collection of any type of music but rather a very specific type of improvisation practice. Therefore, further research is required to be able to generalize the conclusions to more musical genres and other semiotic systems to support the claim that Zipf's laws are not only linguistic universals but are also semiotic system universals. 


\section{References}

Bassano, G. (1585), Ricercate, passaggi et cadentie, Giacomo Vincenzi - Ricciardo Andimo, Venezia.

Bentz, C., \& Ferrer-i-Cancho, R. (2016). Zipf's law of abbreviation as a language universal. In Proceedings of the Leiden Workshop on Capturing Phylogenetic Algorithms for Linguistics (pp. 1-4). University of Tübingen.

Bian, C., Lin, R., Zhang, X., Ma, Q. D., \& Ivanov, P. C. (2016). Scaling laws and model of words organization in spoken and written language. EPL (Europhysics Letters), 113(1), 18002.

Bovicelli, G.B. (1594), Regole, Passaggi di musica..., Venezia.

Brent, M. R. (1999). Speech segmentation and word discovery: A computational perspective. Trends in Cognitive Science, 3, 294-301.

Brunelli, A. (1610), Regole et dichiarationi, Firenze.

Burton, R. (2015, January). The elements of music: What are they, and who cares. In Music: Educating for Life. ASME XXth National Conference Proceedings (pp. 22-28). Parkvill, VIC, Australia: Australian Society for Music Education.

Christiansen, M. H., \& Chater, N. (2016). The now-or-never bottleneck: A fundamental constraint on language. Behavioral and Brain Sciences, 39.

Conforti, G. L. (1593), Breve et facile maniera d'essercitarsi a far passaggi. Rome.

Cowan, N. (2001). The magical number 4 in short-term memory: A reconsideration of mental storage capacity. Behavioral and Brain Sciences, 24(1), 87-114.

Dalla Casa, G. (1584), Il vero modo di diminuir, 2 vols., Angelo Gardano, Venezia. 
Ellis, S. R., \& Hitchcock, R. J. (1986). The emergence of Zipf's law: Spontaneous encoding optimization by users of a command language. IEEE Transactions on Systems, Man, and Cybernetics, 16(3), 423-427.

Farmer, J. D., \& Geanakoplos, J. (2008). Power laws in economics and elsewhere. In Santa Fe Institute.

Ferrer-i-Cancho, R. (2005a). The variation of Zipf's law in human language. The European Physical Journal B-Condensed Matter and Complex Systems, 44(2), 249-257.

Ferrer-i-Cancho, R. (2005b). Zipf's law from a communicative phase transition. The European Physical Journal B-Condensed Matter and Complex Systems, 47(3), 449-457.

Ferrer-i-Cancho, R., Hernández-Fernández, A., Lusseau, D., Agoramoorthy, G., Hsu, M. J., \& Semple, S. (2013). Compression as a universal principle of animal behavior. Cognitive Science, 37(8), 1565-1578.

Ganassi, S. (1535). Opera intitulata Fontegara, Venice; Engl. trans. by H. Peter- D. Swainson, Robert Lienau, Berlin-Lichterfelde 1997.

Gardner, H. E. (2011). Frames of mind: The theory of multiple intelligences. Hachette Uk.

Harris, C. L. (2006). Language and cognition. Encyclopedia of cognitive science, 1-6.

Hsü, K. J., \& Hsü, A. (1991). Self-similarity of the" 1/f noise" called music. Proceedings of the National Academy of Sciences, 88(8), 3507-3509.

Huffman, D. A. (1952). A method for the construction of minimum-redundancy codes. Proceedings of the IRE, 40(9), 1098-1101.

Jusczyk, P. W. (1997). The Discovery of Spoken Language. Cambridge, MA: MIT Press.

Lerdahl, F., \& Jackendoff, R. (1983). A generative theory of tonal music (Vol. 1996). Cambridge, MA: MIT Press. 
Malevergne, Y., Pisarenko, V., \& Sornette, D. (2011). Testing the Pareto against the lognormal distributions with the uniformly most powerful unbiased test applied to the distribution of cities. Physical Review E, 83(3), 036111.

Manaris, B., Romero, J., Machado, P., Krehbiel, D., Hirzel, T., Pharr, W., \& Davis, R. B. (2005). Zipf's law, music classification, and aesthetics. Computer Music Journal, 29(1), 55-69.

Manaris, B., Vaughan, D., Wagner, C., Romero, J., \& Davis, R. B. (2003, April). Evolutionary music and the Zipf-Mandelbrot law: Developing fitness functions for pleasant music. In Workshops on Applications of Evolutionary Computation (pp. 522-534). Springer, Berlin, Heidelberg.

Mandelbrot, B. (1953). An informational theory of the statistical structure of language. Communication Theory, 84, 486-502.

Mandelbrot, B. (1961). On the theory of word frequencies and on related Markovian models of discourse. Structure of Language and its Mathematical Aspects, 12, 190-219.

Miller, G. A. (1956). The magical number seven, plus or minus two: Some limits on our capacity for processing information. Psychological Review, 63(2), 81.

Mitzenmacher, M. (2004). A brief history of generative models for power law and lognormal distributions. Internet Mathematics, 1(2), 226-251.

Narmour, E. (1990). The Analysis and Cognition of Basic Melodic Structures: The Implicationrealisation Model. Chicago: University of Chicago Press.

Narmour, E. (1992). The Analysis and Cognition of Melodic Complexity: The Implicationrealisation Model. Chicago: University of Chicago Press.

Newman, M. E. (2005). Power laws, Pareto distributions and Zipf's law. Contemporary Physics, 46(5), 323-351. 
Ortiz, D. (1553), Tratado de glosas sobre clausulas y otros generos de puntos en la musica de violone, Rome; Engl. trans. by P. Farrell in Journal of the Viola da Gamba Society of America, 4, 1967, pp. 5-9.

Palmer, C. (1989). Mapping musical thought to musical performance. Journal of experimental psychology: human perception and performance, 15(2), 331.

Pearce, M. T., Müllensiefen, D., \& Wiggins, G. A. (2010). Melodic grouping in music information retrieval: New methods and applications. In Advances in Music Information Retrieval (pp. 364-388). Springer, Berlin, Heidelberg.

Piantadosi, S. T. (2014). Zipf's word frequency law in natural language: A critical review and future directions. Psychonomic Bulletin \& Review, 21(5), 1112-1130.

Peretz, I. (1989). Clustering in music: An appraisal of task factors. International Journal of Psychology, 24(2), 157-178.

Poli, G. D. (2004). Methodologies for expressiveness modelling of and for music performance.

Journal of New Music Research, 33(3), 189-202.

Rognoni, R. (1592), Passaggi per potersi essercltare nel diminuire terminatamente, Venezia.

Rognoni-Taeggio, F. (1620), Selva di varii passaggi, Milano.

Rolland, P. Y., \& Ganascia, J. G. (2000). Musical Pattern Extraction and Similarity Assessment. In E. Miranda, editor, Readings in Music and Artificial Intelligence, chapter 7, pages 115-144. Harwood Academic Publishers.

Salge, C., Ay, N., Polani, D., \& Prokopenko, M. (2015). Zipf’s law: balancing signal usage cost and communication efficiency. PLoS One, 10(10), e0139475.

Schenker, H. (2001). Free Composition: Volume III of new musical theories and fantasies (Vol. 3). Pendragon Press. 
Shaffer, L. H. (1984). Timing in solo and duet piano performances. The Quarterly Journal of Experimental Psychology, 36(4), 577-595.

Shannon, C. E. (1948). A mathematical theory of communication. The Bell System Technical Journal, 27(3), 379-423.

Sloboda, J.A. (1982). Music Performance. In D. D Deutsch (ed) The Psychology of Music, 479496, New York: Academic Press.

Spadi, G. B. (1624), Libro de passaggi ascendenti et descendenti, Venezia.

Spevak, C., Thom, B., \& Höthker, K. (2002, September). Evaluating melodic segmentation. In International Conference on Music and Artificial Intelligence (pp. 168-182). Springer, Berlin, Heidelberg.

Studdert-Kennedy, M. (1986). Some developments in research on language behavior. Behavioral and Social Science: 50 Years of Discovery, 208.

Tan, N., Aiello, R., \& Bever, T. G. (1981). Harmonic structure as a determinant of melodic organization. Memory and Cognition, 9(5), 533-539.

Temperley, D. (2001). The Cognition of Basic Musical Structures. Cambridge, MA: MIT Press.

Thom, B., Spevak, C., \& H"othker, K. (2002). Melodic segmentation: Evaluating the performance of algorithms and musical experts. In Proceedings of the International Computer Music Conference (pp. 65-72). San Francisco: ICMA.

Virgiliano, A. (ca. 1600), Il dolcimelo (ms.).

Voss, R. F., \& Clarke, J. (1975). '1/f noise’ in music and speech. Nature, 258(5533), 317-318.

Voss, R. F., \& Clarke, J. (1978). "1/f noise" in music: Music from 1/f noise. The Journal of the Acoustical Society of America, 63(1), 258-263. 


\section{[DRAFT VERSION]}

Warren, R. M., Obusek, C. J., Farmer, R. M., \& Warren, R. P. (1969). Auditory sequence: Confusion of patterns other than speech or music. Science, 164(3879), 586-587.

Zipf, G. K. (1936). The Psychobiology of Language. London: Routledge.

Zipf, G. K. (1949). Human Behavior and The Principle of Least Effort. USA: Addison Wesley. 